\section{Comparing fixation location and stability in patients with neovascular age-related macular degeneration treated with or without Ranibizumab}

E Pearce ${ }^{1}$, S Sivaprasad ${ }^{1}$ and NV Chong ${ }^{2}$

\begin{abstract}
Purpose To compare fixation location and stability in patients with neovascular agerelated macular degeneration (AMD) treated with or without ranibizumab.

Methods Patients were recruited from the Macular Clinic of the King's College Hospital in London. Two groups of patients with neovascular AMD with at least 12 months of follow-up were included in the study. The treated group was treated with ranibizumab while the untreated group did not have any treatment. Best corrected visual acuity (BCVA) with modified ETDRS chart, fixation location and stability as measured with Nidek MP1, central retinal thickness as measured by Zeiss Cirrus SD-optical coherent tomography (OCT), and lesion size as measured by Topcon TRC-50IX camera were analysed and correlated.

Results In total, 102 eyes were included in the study with 76 in the ranibizumab-treated group and 26 in the untreated group. There were no significantly demographic differences between the two groups. However, as expected, the treated group has significantly better vision (48.5 vs 15.5 letters, $P<0.0001$ ) and smaller lesions (10.8 vs $18.3 \mathrm{~mm}^{2}$, $P=0.004)$, the central macular thickness as measured by OCT also showed a trend of normalised macular thickness (252 vs 282 microns, $P=0.07)$. The location of fixation was significantly more central in the ranibizumabtreated group $\left(\chi^{2} 17.9, P<0.0001\right)$ with over $50 \%$ of eyes with predominantly central
\end{abstract}

fixation. Majority $(84.6 \%)$ of the patients in the untreated group had predominantly eccentric fixation. Fixation stability was significantly better in the ranibizumab-treated group as compared with the untreated group, using both the software provided by the MP1 machine $\left(\chi^{2} 21.8, P<0.0001\right)$ and the mean $\log$ bivariate contour ellipse area calculated from the raw data obtained from the machine (3.64 vs 4.39 in treated and untreated group respectively, $P<0.0001)$.

Conclusion Low vision rehabilitation strategy for this group of patients in the ranibizumab era will be very different from those used in untreated patients with dense central scotoma. Further studies on the visual rehabilitation in the ranibizumab-treated patients should consider fixation characteristics of the patients.

Eye (2011) 25, 149-153; doi:10.1038/eye.2010.167; published online 19 November 2010

Keywords: age-related macular degeneration; ranibizumab; fixation; eccentric; visual rehabilitation; low vision

\section{Introduction}

Neovascular age-related macular degeneration (AMD) causes decreased visual acuity and morphological changes in the posterior pole of the fundus that are mainly characterised by the presence of subretinal haemorrhage, intra- and subretinal fluid and/or pigment epithelial
${ }^{1}$ Laser and Retinal Research Unit, King's College Hospital, University of London, London, UK

${ }^{2}$ Oxford Eye Hospital, University of Oxford, Oxford, UK

Correspondence: NV Chong, Oxford Eye Hospital, Headley Way, Oxford, OX3 9DU, UK. Tel: 01865 236736; Fax: 01865 236515; E-mail: victor@eretina.org

Received: 30 April 2010 Accepted in revised form: 31 August 2010; Published online: 19 November 2010

Presentation: Part of the data was presented in ARVO 2009 and Euretina 2009 
detachment (PED) which can be visualised by optical coherent tomography (OCT). Without treatment, most patients develop a disciform scar with destruction of the foveal retinal tissue.

Over time, many patients develop an eccentric area of fixation, there is evidence to suggest that eccentric viewing training might improve reading ability of these patients. Indeed, the Macular Disease Society in the United Kingdom has reported their programme of eccentric viewing training by trained members of the society was a success.

Ranibizumab (Novartis, Basel, Switzerland) is a recombinant, humanised, monoclonal antibody antigenbinding fragment that inhibits all the known isoforms of vascular endothelial growth factor (VEGF-A). Pivotal phase III trials on treatment of neovascular AMD with monthly intravitreal injections of ranibizumab have shown average improvement in visual acuity with a decrease in central macular thickness. ${ }^{1,2}$

There is some evidence to suggest patients with neovascular AMD in the ranibizumab era might be different from those who were previously untreated. In this study, we compared these two groups of patients formally.

\section{Materials and methods}

The study was performed in the Laser and Retinal Research Unit at King's College Hospital. All the measurements adhered to the tenets of the Helsinki agreement; the study was approved by the Clinical Effectiveness department and the Local Ethics Committee.

\section{Inclusion criteria}

Consecutive patients aged 55 years or older with at least 12 months follow-up for ranibizumab therapy for neovascular AMD were included in this study as the treated group. The best corrected visual acuity (BCVA) at baseline of the ranibizumab-treated eye ranged between 24 and 73 ETDRS letters. All lesion subtypes were included. Exclusion criteria were CNVs because of causes other than AMD, previous photodynamic therapy or any other anti-VEGF therapy, vitrectomy or submacular surgery. The untreated eyes had never received any treatment for neovascular AMD. Treatment was not initiated in the latter group because of nonavailability of the drug at the time of presentation or the presenting vision was already too poor to be considered for treatment or the lesion was inactive.

\section{Ranibizumab treatment regimen}

All included patients received three intravitreal injections with ranibizumab at monthly intervals. Decision to re-treat after three injections was based on the following criteria: (1) recurrence of any subretinal fluid or intra-retinal fluid on OCT in a previously dry macula; (2) persistent subretinal fluid or intra-retinal fluid on OCT; (3) new-onset haemorrhages on fundus examination; (4) decrease of five letters or more associated with fluid on OCT or (5) new classic CNV. The numerical changes in central retinal thickness and the presence of serous PED alone without fluid were not taken into account to decide re-treatment.

\section{Visual acuity measurement}

BCVA for each eye was measured using standard ETDRS protocol at $2 \mathrm{~m}$ distance with a modified ETDRS distance chart by a certified examiner on the day of the fixation test. Visual acuity was scored as the total number of ETDRS letters read correctly.

\section{Assessment of location and stability of fixation using MP-1 microperimetry}

The Nidek microperimeter (MP-1, Nidek Instruments, Padova, Italy) was used to measure fixation with a white fixation cross of height $3^{\circ}$ presented on a dark background on the LCD screen of the MP-1. The fixation cross was presented at the maximum luminance of the MP-1. Subjects were asked to look toward the centre of the cross and were encouraged to use peripheral retina if needed. Once subjects had located the cross, fixation was measured for a period of $30 \mathrm{~s}$. Eye position was recorded by tracking a retinal landmark at $25 \mathrm{~Hz}$ throughout the fixation assessment.

The pattern of fixation was classified based on location and stability using the MP-1 software as recommended by Fujii et al..$^{3}$ In brief, the location of fixation is defined as the position of fixation with respect to the centre of the foveal avascular zone, and stability of fixation is defined as the ability of the eye to maintain a stable fixation in the preferred retinal locus (PRL).

The location of fixation was defined as predominantly central fixation (PC) when more than $50 \%$ of the preferred fixation points were located within $2^{\circ}$ of the fovea; poor central fixation (POC) when less than $50 \%$ but more than $25 \%$ of the preferred fixation points were within $2^{\circ}$ of fovea and predominantly eccentric fixation (PE) when less than $25 \%$ of the preferred fixation points were located within the $2^{\circ}$ circle of the fovea.

The stability of fixation was based on the variation of the PRL. The location of fixation was defined as stable 
fixation when more than $75 \%$ of the fixation points were located within a pre-determined limit area of variation of a $2^{\circ}$-diameter circle centred in the gravitational centre of all fixation points, regardless of the position of the foveal centre. The location of fixation was classified as relatively unstable fixation when less than $75 \%$ of the fixation points were located within a $2^{\circ}$-diameter circle, but more than $75 \%$ of the fixation points were located within a $4^{\circ}$-diameter circle. The location of fixation was classified as unstable fixation when less than $75 \%$ of the fixation points were located within a $4^{\circ}$-circle.

\section{Calculation of bivariate contour ellipse area (BCEA)}

Crossland et $a l^{4}$ reported that quantifying fixation stability by calculating a BCEA that encompasses $68 \%$ of fixations is a more powerful and accurate tool than the in-built fixation software of MP-1 for patients with macular diseases. The log BCEA correlated well with reading speed in patients with AMD. Fixation data were collected by the microperimeter (exported as a .mfd text file) over $30 \mathrm{~s}$. The BCEA was calculated using Microsoft Excel (Microsoft Corporation, Seattle, WA, USA) based on the original formula published previously ${ }^{4}$ and the $\log$ BCEA of each study eye was recorded.

\section{Retinal thickness and lesion size measurement}

Central retinal thickness was measured by Zeiss Cirrus HD-OCT (Carl Zeiss Ltd., Welwyn Garden City, UK), and lesion size measurements were based on fluorescein angiogram taken by Topcon TRC 50 IX (Topcon Europe Medical, Capelle, The Netherlands).

\section{Statistical methods}

Patient characteristics were summarised using descriptive statistics and group differences assessed by Student's $t$-test with Microsoft Excel (Microsoft Corporation). Fixation location and stability differences were assessed by $\chi^{2}$-test with online software (http:// www.quantpsy.org $)^{5}$ and Student's $t$-test with Microsoft Excel (Microsoft Corporation).

\section{Results}

\section{Patient characteristics}

In total, 102 eyes were included in the study with 76 in the ranibizumab-treated group and 26 in the untreated group. The demographic and clinical features of the eyes in the ranibizumab-treated group and in the untreated group are summarised in Table 1. The demographic data in terms of age and sex were not significantly different in
Table 1 Patient characteristics

\begin{tabular}{lccc}
\hline & $\begin{array}{c}\text { Untreated } \\
(\mathrm{n}=26)\end{array}$ & $\begin{array}{c}\text { Ranibizumab treated } \\
(\mathrm{n}=76)\end{array}$ & P-value \\
\hline $\begin{array}{l}\text { Mean age in years } \\
\text { Males in \% }\end{array}$ & 80.2 & 79.5 & $P=0.64$ \\
$\begin{array}{l}\text { Mean BCVA in } \\
\text { letters }\end{array}$ & 15.5 & 31.6 & $P=0.52$ \\
$\begin{array}{l}\text { Mean lesion size in } \\
\text { mm }^{2}\end{array}$ & 18.3 & 48.5 & $P<0.0001$ \\
$\begin{array}{l}\text { Mean CMT in } \\
\text { microns }\end{array}$ & 282.2 & 10.8 & $P=0.004$ \\
\hline
\end{tabular}

Abbreviations: BCVA, best corrected visual acuity; CMT, central macular thickness.

Table 2 Location of fixation in the untreated and ranibizumabtreated group

\begin{tabular}{lccc}
\hline & $\begin{array}{c}\text { Untreated } \\
(\mathrm{n}=26)\end{array}$ & $\begin{array}{c}\text { Ranibizumab treated } \\
(\mathrm{n}=76)\end{array}$ & P-value \\
\hline $\begin{array}{l}\text { Fixation location as } \\
\text { Predominantly } \\
\text { central }\end{array}$ & $2(7.7 \%)$ & $40(52.6 \%)$ & \\
$\begin{array}{l}\text { Poor central } \\
\text { fixation }\end{array}$ & $2(7.7 \%)$ & $7(9.2 \%)$ & \\
$\begin{array}{l}\text { Predominantly } \\
\text { eccentric }\end{array}$ & $22(84.6 \%)$ & $29(38.2 \%)$ & $\begin{array}{c}\chi^{2}: 17.9 \\
P<0.0001\end{array}$ \\
\hline
\end{tabular}

the two groups. However, as expected, the untreated group had significantly worse vision and larger lesions, the retinal thickness as measured by OCT also showed a trend of increased macular thickness.

\section{Fixation location in ranibizumab-treated eyes compared with untreated eyes}

The location of fixation was significantly more central in the ranibizumab-treated group with over $50 \%$ with PC

(Table 2). Majority $(84.6 \%$ ) of the patients in the untreated group had PE. The subtype of CNV in the ranibizumabtreated group did not influence the result.

\section{Fixation stability assessment in ranibizumab-treated eyes compared with untreated eyes}

Fixation stability was significantly better in the ranibizumab-treated group as compared with untreated group (Table 3), no matter whether using the software provided by the MP1 machine or the log BCEA from the raw data obtained from the machine.

\section{Discussion}

Ranibizumab, similar to other anti-VEGF agents, is an antipermeability agent and is effective in drying up the macula but has minimal effect on the lesion. ${ }^{6,7}$ Therefore, 
Table 3 Fixation Stability in the untreated and ranibizumab-treated group

\begin{tabular}{|c|c|c|c|}
\hline & Untreated $(\mathrm{n}=26)$ & Ranibizumab treated $(\mathrm{n}=76)$ & P-value \\
\hline \multicolumn{4}{|l|}{ Fixation stability as measured by MP1 } \\
\hline Stable & $3(11.5 \%)$ & $49(64.5 \%)$ & \\
\hline Relatively unstable & $17(65.4 \%)$ & $19(25.0 \%)$ & \\
\hline Unstable & $6(23.1 \%)$ & $8(10.5 \%)$ & $\begin{array}{c}\chi^{2}: 21.8 \\
P<0.0001\end{array}$ \\
\hline \multicolumn{4}{|l|}{ Quantitative analysis of fixation stability } \\
\hline Mean percentages of fixation points within $2^{\circ}$ & 42.3 & 76.2 & $P<0.0001$ \\
\hline Mean percentages of fixation points within $4^{\circ}$ & 75.7 & 91.5 & $\mathrm{P}=0.001$ \\
\hline Mean log BCEA (bivariate contour ellipse area) & 4.39 & 3.64 & $P<0.0001$ \\
\hline
\end{tabular}

unlike other destructive treatment that can destroy the $\mathrm{RPE} /$ photoreceptors, timely ranibizumab modulates the disease process by drying up the macula and reducing the resultant retinal damage caused by the subretinal fluid. So, ranibizumab may help to retain sufficient photoreceptor function and enable stable fixation to be maintained centrally.

In a histopathological study, Green and Enger reported that $48 \%$ of early CNV had preserved photoreceptors in the overlying retina whereas disciform scars were associated with a $75-100 \%$ loss of photoreceptors. ${ }^{8}$ These changes in the neurosensory retina may reflect the pattern of fixation in patients initiated on ranibizumab therapy. Indeed, it may be that the earlier treatment is initiated, the more photoreceptors may be preserved.

Eccentric viewing is an adaptive strategy used by those with bilateral macular disease, whereby the eye is decentred such that a PRL of peripheral retina is used for viewing in place of the damaged fovea. ${ }^{9}$ Although such PRLs have been shown to develop naturally in many cases, ${ }^{10}$ over the past decade, there were several studies focused on eccentric fixation training and low vision rehabilitation strategy to assist patients with disciform scar. ${ }^{11-14}$ The most common training techniques used are reading exercises with optical low vision aids or on closed-circuit television (CCTV), the patient is asked to practise scotoma placement with eye movement control. These techniques require extensive individual patient training and a considerable investment of professional training time for optimum results. ${ }^{15}$

Eccentric viewing training is routinely available in Scandinavia and many centres in the US. Low vision trainers in a US survey agreed that routinely offering eccentric viewing training was of high importance. ${ }^{16}$ The Macular Disease Society in the United Kingdom has reported their programme of eccentric viewing training by trained members of the society was a success. However, any further expansion of the eccentric viewing training in patients with neovascular AMD should be handled with caution.

The ranibizumab-treated patients included in this study were treated in a period when ranibizumab was only just available in the United Kingdom, we would expect that even more patients treated with ranibizumab in the future have central and stable fixation. Low vision rehabilitation strategy for this group of patients in the ranibizumab era will be very different from those used in untreated patients with dense central scotoma.

Fixation stability and location is easy and fast to perform, the software included with the machine appears to be useful. Nonetheless, previous work has suggested that log BCEA is better in predicting reading speed. ${ }^{4}$ Further studies on the

Ranibizumab-treated patients including fixation analysis are needed.

\section{Summary}

What was known before

- Fixation is eccentric and unstable in patients with untreated neovascular age-related macular degeneration.

What this study adds

- Fixation can be central in a significant proportion of neovascular age-related macular degeneration patients treated by Lucentis. Low vision rehabilitation methods might need modification.

\section{Conflict of interest}

The authors declare no conflict of interest.

\section{References}

1 Rosenfeld PJ, Brown DM, Heier JS, Boyer DS, Kaiser PK, Chung CY, et al., MARINA Study Group. Ranibizumab for neovascular age-related macular degeneration. $N$ Engl J Med 2006; 355(14): 1419-1431.

2 Brown DM, Kaiser PK, Michels M, Soubrane G, Heier JS, Kim RY, et al., ANCHOR Study Group. Ranibizumab versus verteporfin for neovascular age-related macular degeneration. N Engl J Med 2006; 355(14): 1432-1444.

3 Fujii GY, De Juan Jr E, Humayun MS, Sunness JS, Chang TS, Rossi JV. Characteristics of visual loss by scanning laser ophthalmoscope microperimetry eyes with subfoveal 
choroidal neovascularization secondary to age-related macular degeneration. Am J Ophthalmol 2003; 136(6): 1067-1078.

4 Crossland MD, Dunbar HM, Rubin GS. Fixation stability measurement using the MP1 microperimeter. Retina 2009; 29(5): 651-656.

5 Preacher KJ. Calculation for the chi-square test: An interactive calculation tool for chi-square tests of goodness of fit and independence (Computer software). Available fromhttp://www.quantpsy.org, 2001.

6 Framme C, Panagakis G, Birngruber R. Invest Ophthalmol Vis Sci 2010; 51(3): 1671-1676.

7 Witkin AJ, Vuong LN, Srinivasan VJ, Gorczynska I, Reichel E, Baumal CR et al. High-speed ultrahigh resolution optical coherence tomography before and after ranibizumab for age-related macular degeneration. Ophthalmology 2009; 116(5): 956-963.

8 Green WR, Enger C. Age-related macular degeneration histopathologic studies. The 1992 Lorenz E. Zimmerman Lecture. Ophthalmology 1993; 100: 1519-1535.

9 Timberlake GT, Peli E, Essock EA, Augliere RA. Reading with a macular scotoma: II. Retinal locus for scanning text. Invest Ophthalmol Vis Sci 1987; 28: 1268.
10 Crossland MD, Culham LE, Kabanarou SA, Rubin GS. Preferred retinal locus development in patients with macular disease. Ophthalmology 2005; 112(9): 1579-1585.

11 Palmer S, Logan D, Nabili S, Dutton GN. Br J Ophthalmol 2010; 94(4): 494-497.

12 Fornos AP, Sommerhalder J, Rappaz B, Pelizzone M, Safran AB. Processes involved in oculomotor adaptation to eccentric reading. Invest Ophthalmol Vis Sci 2006; 47(4): 1439-1447.

13 Stelmack JA, Massof RW, Stelmack TR. Is there a standard of care for eccentric viewing training? J Rehabil Res Dev 2004; 41(5): 729-738.

14 Nilsson UL, Frennesson C, Nilsson SE. Patients with AMD and a large absolute central scotoma can be trained successfully to use eccentric viewing, as demonstrated in a scanning laser ophthalmoscope. Vision Res 2003; 43(16): 1777-1787.

15 Goodrich GL, Mehr EB. Eccentric viewing training and low vision aids: current practice and implications of peripheral retinal research. Am J Optom Physiol Opt 1986; 63(2): 119-126.

16 Stelmack JA, Massof RW, Stelmack TR. Is there a standard of care for eccentric viewing training? J Rehabil Res Dev 2004; 41(5): 729-738. 